\title{
DNA binding specificity of ATAF2, a NAC domain transcription factor targeted for degradation by Tobacco mosaic virus
}

\author{
Xiao Wang ${ }^{1}$ and James N Culver ${ }^{1,2^{*}}$
}

\begin{abstract}
Background: Control of the host transcriptome represents a key battleground in the interaction of plants and pathogens. Specifically, plants have evolved complex defense systems that induce profound transcriptional changes in response to pathogen attack while pathogens have evolved mechanisms to subvert or disable these defenses. Several NAC transcription factors such as ATAF2 have been linked to plant defense responses, including those targeting viruses. The replication protein of Tobacco mosaic virus (TMV) has been shown to interact with and target the degradation of ATAF2. These findings suggest that the transcriptional targets of ATAF2 are involved in defense against TMV.

Results: To detect potential ATAF2 transcriptional targets, a genomic pull-down assay was utilized to identify ATAF2 promoter binding sequences. Subsequent mobility shift and DNA footprinting assays identified a 30-bp ATAF2 binding sequence. An in vivo GUS reporter system confirmed the function of the identified 30-bp binding sequence as an ATAF2 specific transcriptional activator in planta. Gel filtration studies of purified ATAF2 protein and mutagenesis studies of the 30-bp binding sequence indicate ATAF2 functions as a dimer. Computational analysis of interacting promoter sequences identified a corresponding 25-bp A/T-rich consensus sequence with repeating [GC] AAA motifs. Upon ATAF2 induction real-time qRT-PCR studies confirmed the accumulation of select gene transcripts whose promoters contain this consensus sequence.

Conclusion: We report the identification of a cis-regulatory binding sequence for ATAF2. Different from other known NAC protein binding sequences, the A/T-rich ATAF2 binding motif represents a novel binding sequence for NAC family proteins. Combined this information represents a unique tool for the identification of ATAF2 target genes.
\end{abstract}

Keywords: Transcriptional reprogramming, NAC binding, Cis-regulatory sequence

\section{Background}

Plants have evolved sophisticated sensing systems that utilize a multitude of components to translate the perception of a pathogen into the induction of defense responses. In particular, alterations in gene expression as directed by defense-associated transcription factors (TFs) such as ERF, NAC, WRKY, and bZip represent important host responses that occur during pathogen attack [1-3]. In contrast, reprograming gene expression is an important

\footnotetext{
* Correspondence: xiaow@umd.edu
'Institute for Bioscience and Biotechnology Research, University of Maryland,

*Correspondence: xiaow@umd.edu
'Institute for Bioscience and Biotechnology Research, University of Maryland, College Park, MD 20742, USA

${ }^{2}$ Department of Plant Sciences and Landscape Architecture, University of 2Department of Plant Sciences and Landsca
Maryland, College Park, MD 20742, USA
}



strategy pathogens use to disable host defenses and enhance their ability to establish an infection. To counter the induction of these defenses pathogens have evolved mechanisms to override host transcriptional responses either through the targeted disruption of defense associated TFs or through the production of their own factors for controlling transcription $[4,5]$. Characterization of pathogen targeted TFs and the regulatory networks they control are thus essential to developing a full understanding of plant defense responses.

Previously, we reported that the Arabidopsis TF ATAF2 (At5g08790) is induced in response to a Tobacco mosaic virus (TMV) infection and that TMV subsequently targets ATAF2 for degradation through an interaction with the 
viral $126 \mathrm{kDa}$ replication protein [6] . ATAF2 is a member of the NAC (NAM, ATAF1/2, CUC2) family of plant specific TFs and is induced in response to tissue wounding and pathogen infection [6,7]. We also observed that overexpression of ATAF2 resulted in the induction of salicylic acid (SA) mediated defense associated marker genes PR1 and $P R 2$, conversely these genes had reduced transcript levels in ATAF2 knockout or repressor lines [6]. Furthermore, ATAF2 overexpression inhibited TMV accumulation in inoculated tissues. These findings suggest that ATAF2 plays a role in the regulation of host basal defense responses and that TMV targets ATAF2 for degradation as a means to disrupt these defense pathways.

NAC domain TFs such as ATAF2 make up a large plant specific family of proteins with 105 NAC genes in Arabidopsis and $\sim 75$ in rice [8]. All members within this family contain a highly conserved $\mathrm{N}$ terminal NAC domain and a divergent C-terminal transcription activation region (TAR). NAC genes have been widely reported to be involved in plant morphogenesis/organ development, senescence and abiotic/ biotic stresses [9-13]. In addition, several NAC proteins are reported to interact with viral proteins. These include interactions between the NAC containing GRAB proteins and the Geminivirus RepA protein [14] and the Arabidopsis TIP protein with the Turnip crinkle virus coat protein [15]. These interactions are implicated in the modulation of virus replication and the induction of host defense responses. Combined these findings suggest that NAC domain proteins are key TFs controlling molecular pathways that are of importance to virus biology.

To further understand the role of ATAF2 in virus biology we utilized a genomic pull-down assay to identify potential ATAF2 target sequences from the Arabidopsis genome. An analysis of the DNA sequences bound by ATAF2 led to the identification of a 25-bp ATAF2 specific consensus binding sequence. This binding sequence is sufficient to promote ATAF2 mediated gene transcription and is unique in comparison to previously reported NAC protein binding domains [16,17].

\section{Results}

\section{Identification of ATAF2 binding sequences}

ATAF2 binding sequences were identified via an immuno-pull-down assay using purified hexa-histidine tagged ATAF2 and genomic DNA isolated from Arabidopsis thaliana ecotype Shahdara. In addition, a hexahistidine tagged ATAF2 deletion construct, $\triangle$ ATAF2, lacking the putative DNA binding subdomains $\mathrm{C}$ and $\mathrm{D}$, nucleotides 172 - 377, was used as a negative control (Figure 1A). In this assay the hexa-histidine tagged ATAF2 or $\triangle \mathrm{ATAF} 2$ proteins were mixed with EcoRI

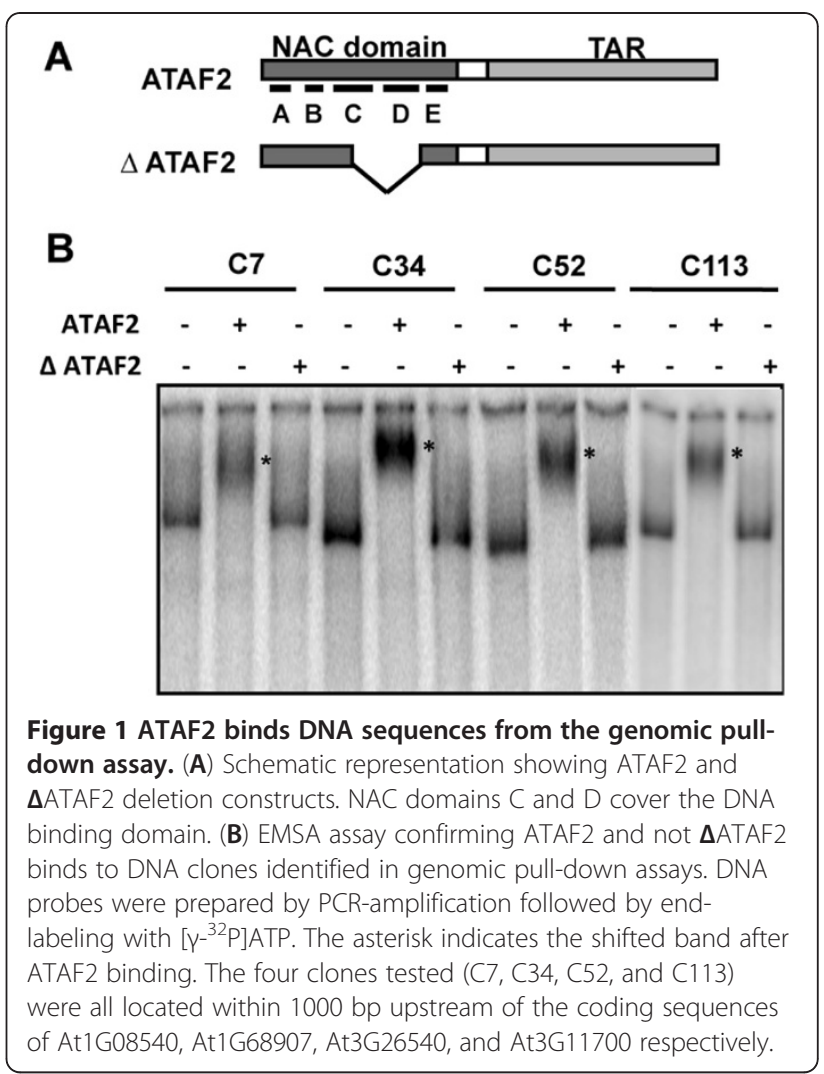

and TaqI cut Shahdara genomic DNA and precipitated using anti-PolyHis antibody [18]. Both ATAF2 and $\triangle$ ATAF2 bound DNA fragments were subsequently PCR-amplified and cloned into a plasmid vector. The number of DNA clones derived from ATAF2 bound complexes ( $\sim 600$ clones) were 50 -fold higher than that derived from $\triangle$ ATAF2 bound complexes (12 clones), reflecting the deletion of the putative DNA binding regions. Of 97 ATAF2 clones randomly selected for sequencing 47 were located upstream and within 3000 basepairs (bp) of a known or predicted genomic translational start site (Table 1).

To confirm that ATAF2 binds to the immunoprecipitated genomic DNA fragments, a representative group of four clones covering sequences within $1000 \mathrm{bp}$ of the translational start sites for At1g08540, At1g68907, At3g26540, and At1g01210 were selected for electrophoretic mobility shift assay (EMSA) using purified recombinant hexa-histidine tagged ATAF2. We speculated that proximity to a translational start site would enhance the likelihood that these sequences function in ATAF2mediated gene regulation. DNA fragments from the four selected clones were prepared by PCR amplification and $\mathrm{P}^{32}$ end-labeled. Gel shift assays for all tested clones produced a mobility shift in the presence of purified ATAF2 protein but not in the presence of purified $\triangle \mathrm{ATAF} 2$ protein (Figure 1B). 
Table 1 Putative ATAF2 target genes identified via a genomic pull-down assay

\begin{tabular}{|c|c|c|}
\hline Clone \# & AGI & Annotation \\
\hline$C 7^{*}$ & AT1G08540 & RNA Polymerase sigma subunit \\
\hline C9 & AT3G61111 & Structural constituent of ribosome \\
\hline $\mathrm{C} 18^{*}$ & AT5G61810 & Pentatricopeptide (PPR) repeat-containing protein \\
\hline $\mathrm{C} 20$ & AT5G39460 & F-box family protein \\
\hline $\mathrm{C} 22$ & AT2G38940 & AtPT2, phosphate transporter 2 \\
\hline $\mathrm{C} 23$ & AT4G24660 & Homeobox protein 22, AtHB22 \\
\hline $\mathrm{C} 25$ & AT3G44470 & Transposable element gene \\
\hline $\mathrm{C} 28^{*}$ & AT4G07840 & Transposable element gene \\
\hline $\mathrm{C} 30^{*}$ & AT5G24350 & Unknown protein \\
\hline $\mathrm{C} 32^{*}$ & AT2G28390 & SAND family protein \\
\hline C33 & AT2G02840 & Unknown protein \\
\hline $\mathrm{C} 34^{*}$ & AT1G68907 & Defensin-like (DEFL) family protein \\
\hline C37 & AT4G05150 & Octicosapeptide/Phox/Bem1p (PB1) domain-containing protein \\
\hline $\mathrm{C} 38$ & AT1G26620 & Unknown protein \\
\hline $\mathrm{C} 39^{*}$ & AT1G08370 & DCP1 involved in mRNA decapping \\
\hline $\mathrm{C} 41$ & AT1G59820 & AMINOPHOSPHOLIPID ATPASE3 \\
\hline C42 & AT1G70170 & Matrix metalloproteinase, MMP \\
\hline$C 45^{*}$ & AT3G19080 & SWIB complex BAF60b domain-containing protein \\
\hline C49 & AT1G55060 & Ubiquitin-like gene \\
\hline $\mathrm{C} 52^{*}$ & AT3G26540 & Pentatricopeptide (PPR) repeat-containing protein \\
\hline C56 & AT3G57220 & UDP-GICNAc:dolichol phosphate N-acetylglucosamine-1-phosphate transferase \\
\hline C58 & AT1G01210 & DNA-directed RNA polymerase III family protein \\
\hline C59 & AT5G21482 & Cytpkinin oxidase \\
\hline C64 & AT1G14180 & Protein binding / zinc ion binding \\
\hline $\mathrm{C} 65^{*}$ & AT3G01880 & Unknown protein \\
\hline $\mathrm{C} 66^{*}$ & AT5G27902 & Transposable element gene \\
\hline $\mathrm{C} 81$ & AT2G37160 & Transducin family protein / WD-40 repeat protein \\
\hline $\mathrm{C} 83^{*}$ & AT4G13440 & Calcium-binding EF hand family protein \\
\hline $\mathrm{C} 85$ & AT3G22300 & Nuclear-encoded gene for mitochondrial ribosomal small subunit protein $\mathrm{S} 10$ \\
\hline C87 & AT4G09584 & Unknown pseudogene \\
\hline C92 & AT3G53365 & Unknown gene \\
\hline C96 & AT5G13190 & Unknown protein \\
\hline C98 & AT3G56600 & Inositol or phosphatidylinositol kinase/ phosphotransferase \\
\hline $\mathrm{C} 100^{*}$ & AT1G70070 & EMB25, Embryo defective 25 \\
\hline $\mathrm{C} 104^{*}$ & AT3G62060 & Pectinacetylesterase family protein \\
\hline C107 & AT4G01533 & Unknown gene \\
\hline $\mathrm{C} 108^{*}$ & AT4G19570 & DNAJ heat shock $\mathrm{N}$-terminal domain-containing protein \\
\hline C109 & AT3G10912 & CPUORF63 \\
\hline $\mathrm{C} 110^{*}$ & AT4G22980 & Unknown protein \\
\hline C111 & AT2G12230 & Pseudogene, C-1-tetrahydrofolate synthase \\
\hline $\mathrm{C} 113^{*}$ & AT3G11700 & FASCICLIN-LIKE ARABINOGALACTAN PROTEIN 18 PRECURSOR, FLA18 \\
\hline C115 & AT4G20010 & Plastid transcriptionally active 9 (PTAC9) \\
\hline $\mathrm{C} 116^{*}$ & AT5G56550 & Oxidative stress 3 (OXS3) \\
\hline $\mathrm{C} 120^{*}$ & AT1G24070 & Transposable element gene \\
\hline
\end{tabular}


Table 1 Putative ATAF2 target genes identified via a genomic pull-down assay (Continued)

\begin{tabular}{lll}
\hline $\mathrm{C} 121$ & AT3G33100 & Transposable element gene \\
$\mathrm{C} 123^{*}$ & At3G59050 & Polyamine oxidase 3 (ATPAO3) \\
$\mathrm{C} 131^{*}$ & AT1G33010 & F-box family protein \\
\hline
\end{tabular}

The identified ATAF2 interacting sequences were upstream and within 3000 bp of a translation start codon. Those marked by an * are upstream and within $1000 \mathrm{bp}$ of a start codon.

\section{Identification of a $30-\mathrm{bp}$ ATAF2 binding sequence}

One clone showing a strong mobility shift in the presence of ATAF2, designated C34, was selected for further studies aimed at identifying the specific DNA sequences targeted by ATAF2. The C34 DNA clone is located upstream (-64 nt to $-982 \mathrm{nt}$ ) of the coding region for the Arabidopsis defensin-like protein At1g68907. To determine the likelihood that the defensin-like gene was regulated by ATAF2 and thus a good candidate gene for further analysis, we examined its expression levels in two independent Arabidopsis ecotype Shahdara ATAF2 overexpression lines as well as in response to tissue wounding (Figure 2A) [6]. Quantitative RT-PCR analysis showed At1g68907 was transcriptionally induced by an average $\sim 4$-fold in the two ATAF2 overexpression lines as well as in wounded Shahdara leaf tissues where expression of ATAF2 is also induced (Figure 2A). Transcriptional induction of At1g68907 thus corresponds with ATAF2 expression, either by transgene overexpression or wound induction of the endogenous gene, consistent with a role for ATAF2 in the regulation of this gene.
To narrow down the ATAF2 binding sequence the C34 fragment was sub-divided into three segments and each fragment was examined by EMSA for ATAF2 binding (Figure 2B). The second 300-bp fragment, F300-2, showed significant binding activity while the third fragment F300-3 showed relatively weak binding activity and the first fragment, F300-1, displayed no binding activity (Figure 2C). None of the fragments bound to $\triangle \mathrm{ATAF} 2$ (Figure 2C). Fragments, F300-2 and F300-3 were further subdivided into four $\sim 150$-bp fragments. A 150-bp fragment, 150-1, from F300-1, which showed no ATAF2 binding activity, was used as a negative control. Results indicated that fragment 150-3, covering nt -493 to -349 from the original 918-bp C34 clone was responsible for the observed ATAF2 binding (Figure 2D).

DNase I footprinting was used to identify the specific region of the interacting 150-3 C34 fragment protected by ATAF2 binding. Results demonstrated that only one region was substantially protected from DNase I digestion (Figure $3)$. Sequence analysis of this region revealed it to be a 30-bp sequence (nt -428, TCAGAAGAGCAATCAAATTAAAAC

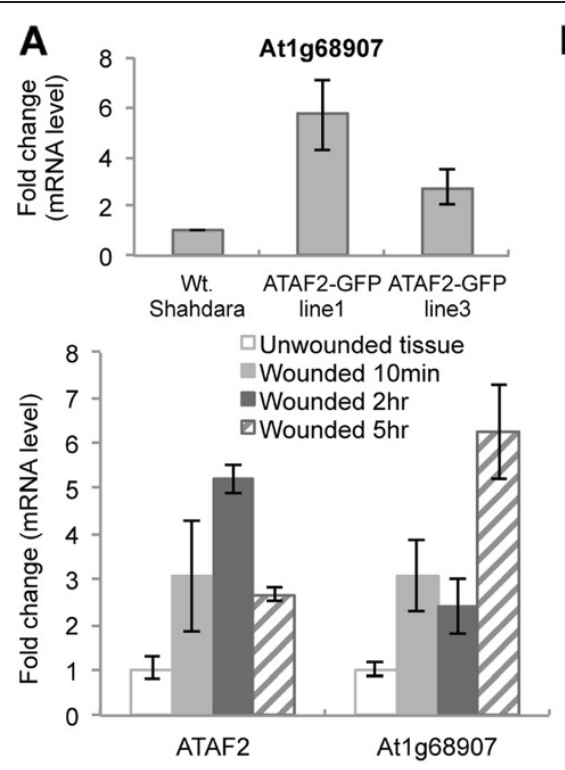

B

C34 - At1g68907 Defensin-like family protein

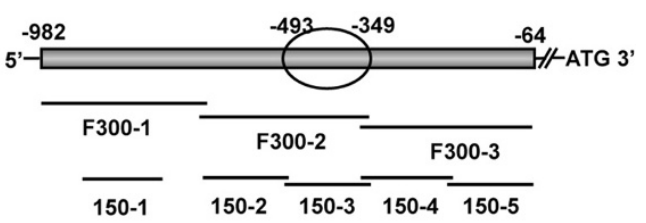

C



Figure 2 ATAF2 induces the transcription and binds to a 150-bp fragment within the promoter region of a defensin-like family protein (At1g68907). (A) Real-time qRT-PCR showing enhanced expression of At1g68907 in two 35S::ATAF2-GFP overexpression lines and in wounded Arabidopsis Shahdara plant tissue. RNA was extracted from five independent test plants. The data represents the average \pm standard deviation from duplicate qRT-PCR reactions. (B) Schematic representation of the At1g68907 promoter fragment investigated for ATAF2 binding activity. EMSA assay showing ATAF2 binds to the DNA fragments F300-2 (C) and 150-3 (D) in the promoter region of At1G68907. The asterisk indicates the shifted band after ATAF2 binding. 


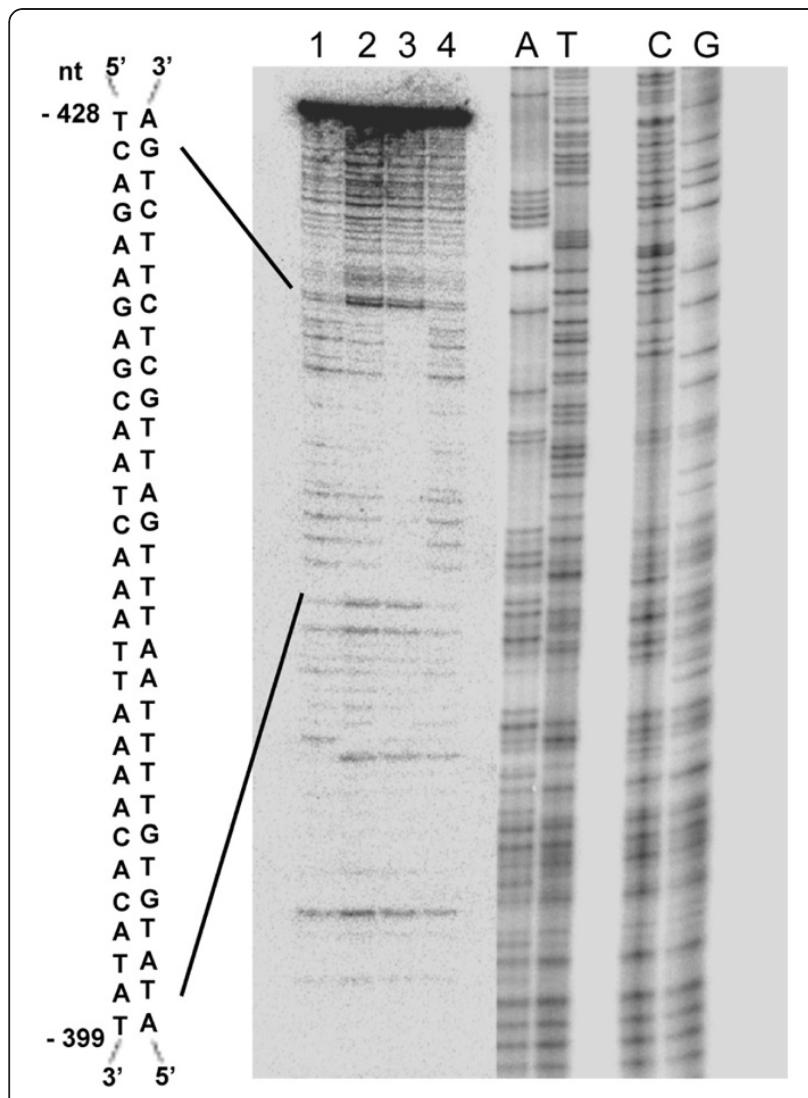

Figure 3 DNase I footprinting analysis showing ATAF2 binds and protects a 30 -bp sequence within the 150-3 promoter fragment of At1G68907. The sequence of the protected region is shown on the left. Lane 1, no protein added; lane 2, 5 mM ATAF2 added; lane 3, 25 mM ATAF2 added; lane 4, 25 mM $\triangle$ ATAF2 added. Sequencing ladders ( $A, T, C, G$ ) were run in adjacent lanes to provide a positional reference.

ACATAT, nt -399). This protected region likely represents an ATAF2 cis-regulatory element.

\section{ATAF2 30-bp binding sequence functions in transcriptional activation}

To determine if the identified 30-bp segment was sufficient to promote in vivo transcriptional activation by ATAF2, we first used a yeast lacZ reporter system to determine if the ATAF2 and $\triangle$ ATAF2 constructs, both of which contain the putative transcriptional activation region, can function as transcriptional activators in yeast when fused to the LexA DNA-binding domain (Figure 4A). Results indicated that when fused to the LexA DNA binding domain both ATAF2 and $\triangle$ ATAF2 proteins function in the transcriptional activation of the $L a c Z$ open reading frame (Figure $4 \mathrm{~A}$ ). Thus, given the presence of a DNA specific binding domain both ATAF2 constructs can function as transcriptional activators.

To confirm the in planta function of the identified 30bp cis-regulatory element in ATAF2-mediated gene expression, reporter constructs containing either two (2X) or four (4X) tandem repeats of the 30-bp sequence were engineered upstream $(-49 \mathrm{nt})$ of the minimal $35 \mathrm{~S}$ CaMV promoter and investigated for the ability to drive $\beta$-glucuronidase (GUS) transcription (Figure 4B). The resulting GUS reporter constructs were agroinfiltrated into leaves of Nicotiana benthamiana in combination with 35S agro-expression constructs for ATAF2, $\triangle \mathrm{ATAF} 2$ or an empty cassette vector. Results revealed little GUS activity in plant tissues co-infiltrated with either the $2 \mathrm{X}$ or $4 \mathrm{X}$ repeat constructs and the empty cassette vector (Figure 4B). However, when the ATAF2 expression vector was co-infiltrated with either the $2 \mathrm{X}$ or $4 \mathrm{X}$ repeat constructs, GUS activity dramatically increased (Figure 4B). In contrast, the $35 \mathrm{~S}$ minimal promoter construct yielded little GUS activity when co-expressed with the ATAF2 expression vector. Furthermore, the co-expression of $2 \mathrm{X}$ or $4 \mathrm{X}$ repeat constructs with the $\triangle \mathrm{ATAF} 2$ construct, which lacks the putative ATAF2 DNA binding domain, also failed to induce significant GUS activity (Figure 4B). Combined these results indicate that ATAF2 can utilize the identified 30-bp regulatory binding element in vivo for transcriptional activation.

\section{TMV infection increases GUS activity driven by the 30-bp} ATAF2 binding element

Previously, we demonstrated the transcriptional induction of ATAF2 within TMV inoculated leaf tissues [6]. To determine whether the identified 30-bp binding sequence functions in response to ATAF2 produced endogenously during an infection, TMV inoculated Arabidopsis leaf tissues were agro-infiltrated with either the $2 \mathrm{X}$ or $4 \mathrm{X}$ GUS reporter constructs at $4 \mathrm{dpi}$. GUS activity was quantified two days post agro-infiltration. Both the levels of ATAF2 mRNA as well as GUS activity increased within agroinfiltrated mock-inoculated tissues, indicating that agroinfiltration alone is sufficient to induce ATAF2 (Figure 5A). However, within TMV infected tissues, both $2 \mathrm{X}$ and $4 \mathrm{X}$ constructs containing the 30 -bp regulatory sequence displayed significantly greater increases in GUS activity (averaging $\sim 2$-fold increases across treatments) than observed in mock-inoculated tissues or tissues infiltrated with the $35 \mathrm{~S}$ minimal promoter construct (Figure $5 \mathrm{C}$ ). This result corresponds with the higher levels of ATAF2 mRNA detected in the TMV infected leaves (Figure 5A and $\mathrm{B})$. These findings are consistent with the induction of ATAF2 in response to TMV infection and indicates that the 30-bp binding element is a functional target of endogenously expressed ATAF2.

\section{Mutational analysis of the ATAF2 binding element}

To analyze the identified ATAF2 binding element, three substitutions replacing 5 to 6 nucleotides within the 30- 

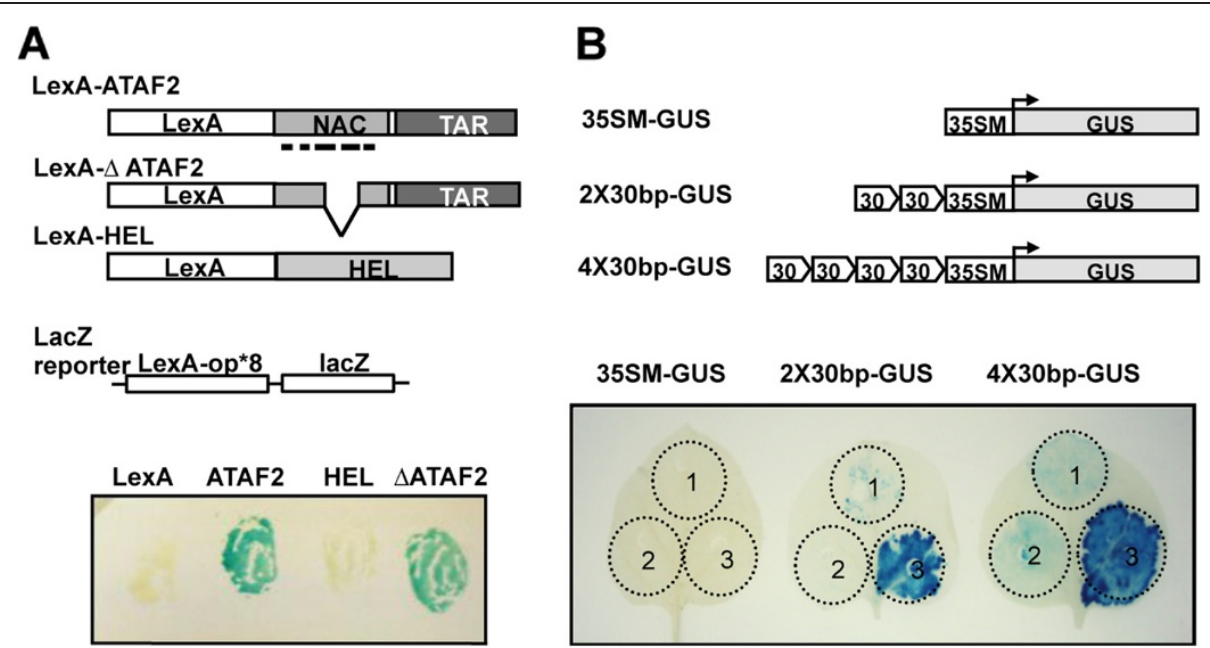

Figure 4 ATAF2 functions as a transcriptional activator. (A) $\beta$-galactosidase (LacZ) assay indicating both ATAF2 and $\triangle$ ATAF2 are capable of activating lacZ expression in yeast. L40 yeast expressing an integrated Lac-Z reporter were transformed with constructs LexA (empty), LexAATAF2, LeXA-HEL, or LeXA- $\triangle A T A F 2$. HEL represents TMV encoded helicase domain and was used as a negative control. (B) ATAF2, but not $\triangle$ ATAF2, trans-activates GUS expression via the $30 \mathrm{bp}$ ATAF2 binding sequence. The reporter constructs 35SM-GUS, 2X30bp-GUS, or 4X30bp-GUS were co-expressed with the pBin empty vector (circle 1), pBin/ $\triangle$ ATAF2 (circle 2) or pBin/ATAF2 (circle 3) in N. benthamiana leaves.

bp binding sequence were created and tested both in vitro and in vivo (Figure 6A). Substitutions were designed to alter segments of the binding element to determine if any specific region played a greater role in ATAF2 binding. The first mutation covers nts 3-7, replacing AGAAG with TTTTT (designated as C1). The second mutant covers nts $13-18$, substituting TCAAAT to GTCCCC (designated as C2). The third mutant covers nts 22-27, exchanging AACACA to TTTTTT (designated as C3). EMSA results showed that all three substitutions displayed substantial reductions of $>85 \%$ in ATAF2 binding, suggesting that the entire sequence is required for ATAF2 binding (Figure 6B).

ATAF2 binding elements carrying the $\mathrm{C} 1, \mathrm{C} 2$, and $\mathrm{C} 3$ were also introduced into the Agrobacterium 2X-GUS reporter construct and tested for GUS activity when coexpressed with ATAF2 in $N$. benthamiana leaves. In these assays, all three substitutions displayed $>50 \%$ reductions in the levels of GUS activity when compared to the unmodified binding element 2X-GUS construct
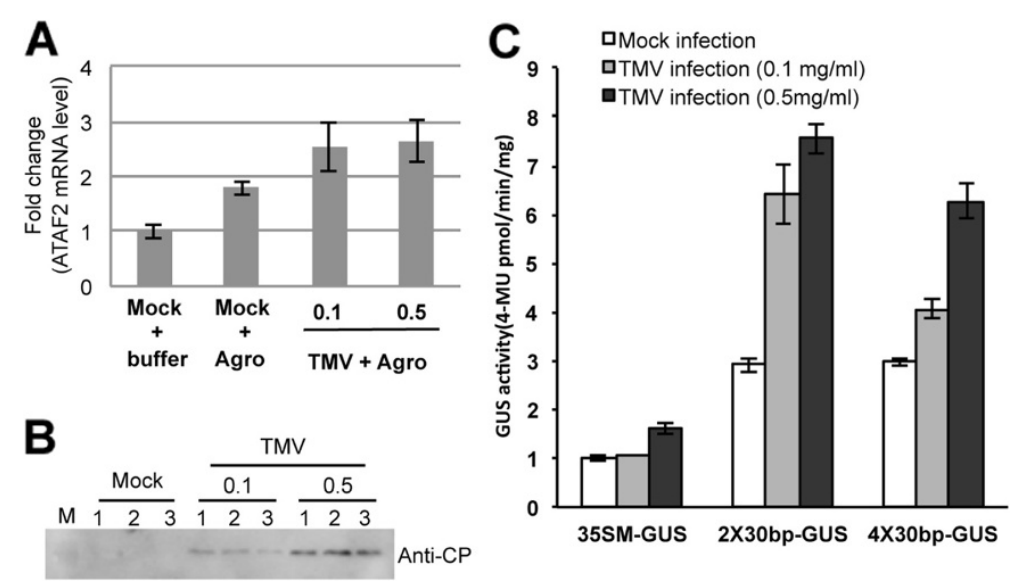

Figure 5 TMV infection enhances GUS activity driven by the ATAF2 binding sequence. (A) Real-time qRT-PCR analysis showing increased ATAF2 expression in Agro-infiltrated and TMV-inoculated tissues at $6 \mathrm{dpi}$. Numbers 0.1 and 0.5 are the $\mathrm{mg} / \mathrm{ml}$ of virus used for inoculation. RNA was extracted from three independent test plants. Data represents average \pm standard deviation from triplicate qRT-PCR reactions. (B) TMV coat protein specific Western-blot showing the level of virus accumulation in three independent samples of TMV-inoculated tissues. (C) Enhanced GUS activity observed in TMV-inoculated tissues. At four dpi TMV-infected Arabidopsis plants were agro-infiltrated with the $35 \mathrm{~S}$ minimal promoter (35SM-GUS), the 2X30bp-GUS, or the 4X30bp-GUS reporter constructs. At six dpi tissue punches from three independent leaves were collected and tested by fluorometric assay for GUS activity. Data represents the average \pm standard deviation. 


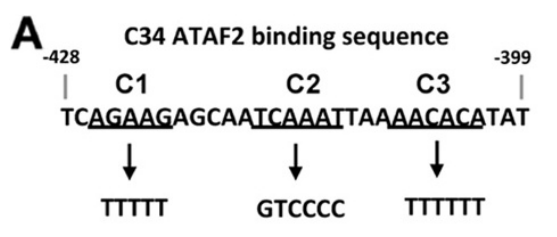

B



Figure 6 Mutations within the 30-bp sequence affect ATAF2-DNA binding activity. (A) Schematic diagram of mutants created within the 30-bp ATAF2 binding sequence. (B) EMSA assay showing all three mutations have reduced ATAF2 binding activity. (C) Both GUS staining assay and GUS quantification assay confirming that all three mutants affected ATAF2-DNA binding activity in vivo. Tissues punches from three independent leaves were collected at two days post agro-infiltraton and tested by fluorometric assay for GUS activity. Data represents the average \pm standard deviation.

(Figure 6C). This finding is consistent with the EMSA analysis and indicates that the entire binding element is required for full activity.

To further investigate the ATAF2 binding sequence a series of six two-base substitutions within the identified 30-bp DNA fragment were created and tested for their effects on ATAF2 binding (Figure 7A). From gel shift assays, mutations M1 (base substitutions from AG to $\mathrm{CA}$ at nt position 3 and 4), M4 (TT to CC at nt position 18 and 19), and M5 (AC to GA at nt position 23 and 24) showed the most dramatic reduction in ATAF2 binding activities of 91\%, 87\%, and 96\%, respectively (Figure 7A \& B). Mutation M3 (TC to GA at nt position 13 and 14) showed a partial reduction of $47 \%$ (Figure 7B). The other two mutations M2 and M6 did not dramatically reduce the binding of ATAF2 to the identified $30 \mathrm{bp}$ element (Figure 7B). These findings further indicate that sequences covering nearly the entire 30 -bp binding domain contribute to ATAF2 binding.

\section{Dimerization of the ATAF2 NAC domain}

Having demonstrated that nearly the entire 30-bp sequence is required for optimal ATAF2 binding, we speculated that ATAF2 may function as a dimer or multimer, similar to other reported NAC domain proteins $[19,20]$. To characterize the quaternary structure of ATAF2, the ATAF2 DNA-binding domain (NAC domain) was expressed from bacteria and the purified protein examined using size-exclusion chromatography. Results indicate that the purified ATAF2 NAC domain peptide eluted as a protein of around $\sim 44 \mathrm{kDa}$, which is
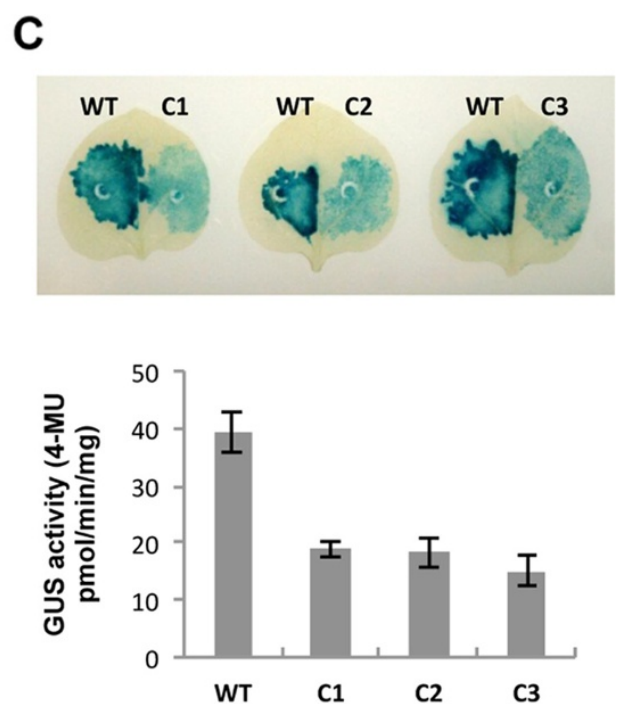

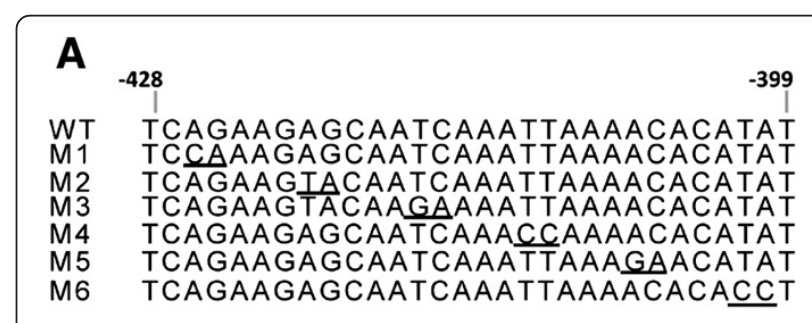

B

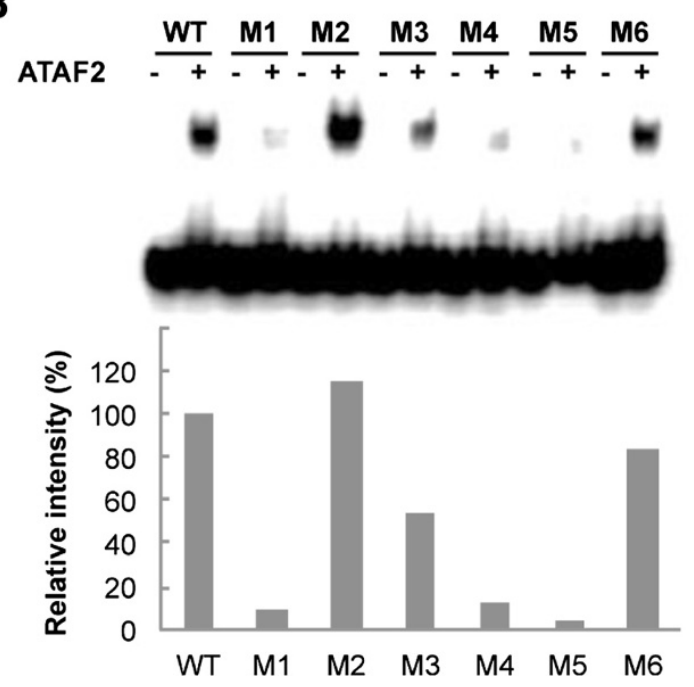

Figure 7 Scanning mutagenesis analysis of the ATAF2 binding sequence. (A) Six different two base substitutions (M1 - M6) were created within the 30-bp binding sequence. Specific mutations are underlined. (B) EMSA assays testing ATAF2-binding activity. The binding activity was expressed relative to ATAF2 binding to wild-type 30-bp sequence as 100\%. 
twice the molecular weight of the monomeric NAC domain $(22.8 \mathrm{kDa})$ (Figure $8 \mathrm{~A} \mathrm{\&} \mathrm{B})$, indicating that the DNA binding domain of ATAF2 forms a dimer.

\section{ATAF2-mediated regulation of selected pull-down sequences}

To examine the ability of ATAF2 to alter the transcription of genes identified in the pull down assay, a group of nine genes were selected and examined by real-time qRT-PCR for expression in both wounded wild-type and wounded ATAF2 knockout (KO) line (SALK_136355) leaf tissues. Wounding was used to induce endogenous ATAF2 expression with tissues harvested after 5 hours [6,7]. Genes were selected based on the location of an ATAF2 binding sequence within $1000 \mathrm{bp}$ of a translational start codon. In addition, defensin-like protein At1g68907, corresponding to clone C34, was included in the group as a control. Consistent with our previous results the transcript of At1g68907 showed a reduced accumulation in wounded tissues from the ATAF2 KO line (Table 2). Furthermore, 7 of the 8 additional transcripts examined showed at least a two-fold reduction in accumulation within wounded tissues of the ATAF2 KO line (Table 2). These findings indicate that a significant portion of the genes whose promoter sequences were pulled-downed by ATAF2 are directly affected by its presence and are thus likely to carry a functional ATAF2 binding sequence.

\section{Identification of an ATAF2 consensus binding sequence}

To expand upon the characterization of the ATAF2 binding sequence, pull-down sequences that were within $1000 \mathrm{bp}$ of a translational start site and showed ATAF2 binding via EMSA and / or displayed altered transcript accumulations in ATAF2 $\mathrm{KO}$ plants were selected for motif analysis using the program MEME [21,22]. This selection criteria yielded eight different pull-down clones for which there was secondary evidence supporting ATAF2 binding. MEME analysis of these pull-down sequences revealed a consensus 25-nt sequence that corresponded to the 30-bp sequence identified above from the original C34 clone (Figure 9). The consensus sequence is predominantly $\mathrm{A} / \mathrm{T}$ rich, but does contain repeating [CG]AAA motifs in forward or reverse orientations. Subsequently we expanded our analysis to 21 of the original clones identified by pull-down assay that were upstream and within $1000 \mathrm{bp}$ of a known or predicted translational start site. MEME analysis of these genes also identified a similar $\mathrm{A} / \mathrm{T}$ rich sequence within each of the additional clones (Table 1).

\section{Discussion}

The induction of basal resistance responses can significantly impact virus accumulation and spread even within a susceptible host [23]. Thus, methods aimed at



enhancing basal resistance could provide novel approaches for creating new forms of disease resistance. A number of studies indicate that SA mediates several anti-viral pathways that contribute to host basal defenses $[23,24]$. Recent studies by Lee et al., [25] suggest that during TMV infections SA-mediated signaling controls resistance mechanisms that involve the alternative oxidase pathway, RDR1 mediated RNA silencing systems, and other as yet uncharacterized defenses. These findings indicate that anti-viral defenses require the regulation of multiple host processes. Subsequently, viruses likely encode multiple countermeasures aimed at overcoming these defenses. The targeted degradation of ATAF2 by TMV suggests that this TF regulates host processes that affect the infection cycle. This possibility is supported by studies that show overexpression of ATAF2 leads to the induction of defense related genes and enhanced plant resistance to TMV [6]. In contrast, T-DNA knockout or transcription repressor plant lines show a marked decrease in the activation of these defense-associated genes. In particular, SA associated 
Table 2 Gene expression analysis on ATAF2 candidate target genes

\begin{tabular}{lllcc}
\hline $\begin{array}{l}\text { Clone } \\
\text { number }\end{array}$ & AGI & Annotation & $\begin{array}{c}\text { Wt Col. } \mathbf{~ h r} \text { wounded vs. } \\
\text { non-wounded* }\end{array}$ & $\begin{array}{c}\text { ATAF2 KO-136355 } \mathbf{5} \text { hr wounded vs. } \\
\text { non-wounded** }\end{array}$ \\
\hline \multirow{2}{*}{ C7 } & AT5G08790 & ATAF2 & 5.37 & 1 \\
C32 & AT1G08540 & RNA Polymerase sigma subunit & 1.42 & 0.47 \\
C34 & AT2G28390 & SAND family protein & 1.64 & 0.91 \\
C52 & AT1G68907 & Defensin-like (DEFL) family protein & 3.63 & 0.99 \\
C104 & AT3G26540 & Pentatricopeptide (PPR) repeat-containing & 2.00 & 0.78 \\
C108 & AT3G62060 & Protein & & 1.06 \\
C113 & AT4G19570 & DNAJ heat shock N-terminal domain- & 2.91 & 2.17 \\
C116 & AT3G11700 & Fasciclin-like arabinogalactan protein & 8.06 & 1.02 \\
C123 & AT5G56550 & Oxidative stress 3, OXS3 & 3.69 & 1.55 \\
\hline
\end{tabular}

* qRT-PCR analysis of ATAF2 and selected candidate ATAF2 target genes at 5 hrs post leaf wounding vs non-wounded tissues. Fold changes are the average of two independent experiments. For each experiment leaf RNA was pooled from 5 individual test plants and qRT-PCR reactions were run in duplicate and normalized to $18 \mathrm{~s}$ rRNA levels.

Wild-type Columbia and ATAF2 knock-out (Salk_136355) plants were mechanically wounded 5 hr prior to RNA extraction.

\begin{tabular}{|c|c|c|c|c|}
\hline \multicolumn{5}{|c|}{ [GA]A[AG][AG]A[GT][CG]A[AG][AT][AC]AAA[GCT][AT]AAA[AGT][CA]A[ACG]A[GTA] } \\
\hline \multirow{2}{*}{$\frac{\text { Name }}{30 \mathrm{bp}}$} & \multirow{2}{*}{$\frac{p \text {-value }}{4.68 \mathrm{e}-10}$} & \multicolumn{3}{|c|}{ Sites } \\
\hline & & TCA & GAAGAGCAATCAAATTAAAACACAT & AT \\
\hline C-52 & $8.66 \mathrm{e}-12$ & ATAGATTACA & GAAAATGAAAAAAACAAAAACAAAG & TTACATCTCA \\
\hline C-116 & $3.13 e-09$ & GTGAGTTAAG & AAAAACCAAAAAAACAAAAACCAAA & AAGCTGTGAT \\
\hline C-34 & $3.46 e-09$ & AGCGAGATCA & GAAGAGCAATCAAATTGAAACACAT & ACTAGTTGTG \\
\hline C-7 & $5.56 \mathrm{e}-09$ & TTGAGATGAT & CAAAAGCCAGAAAAGAAAAGAAAAG & AAAAGAGCTT \\
\hline C-104 & $1.22 \mathrm{e}-08$ & AAATGATTTT & GAAAAAGAAAAAGAGTAAAGCAGAA & TGATTTCTAA \\
\hline$C-123$ & $5.76 e-08$ & ATTTGTTCTC & AAGGTTCAGAAAAACAAAATAAAAG & GATAGATTGG \\
\hline C-113 & $6.87 e-08$ & GTGAAGCAAA & GAGAAGCAGCCGAAGAAGAAGGGAG & AACACGTGGC \\
\hline$C-108$ & $8.15 e-08$ & AGTGGTTTAT & AGAAATGTAAAAAAGGAAATCAAAT & CTTCGTTTAG \\
\hline \multicolumn{5}{|c|}{$\begin{array}{l}\text { Figure } 9 \text { Identification of the ATAF2 consensus binding sequence. MEME analysis utilized the eight pull-down sequences listed. These } \\
\text { sequences are all within } 1000 \text { bp upstream of a translational start site and were selected based on their ability to bind ATAF2 and / or display } \\
\text { altered transcript accumulations of the corresponding mRNA in ATAF2 knockout plants. Brackets within the consensus sequence indicate the } \\
\text { range of bases found at that position. }\end{array}$} \\
\hline
\end{tabular}


defense genes including $P R 1$ and $P R 2$ are reduced in transcriptional activation in the absence of ATAF2, either by knockout, transcriptional repression or TMV directed degradation [6]. These findings indicate that ATAF2 functions to enhance host basal defense processes and that its targeted degradation represents a potential TMV-directed counterdefense mechanism.

To better understand the ability of ATAF2 to regulate host gene expression we sought to characterize ATAF2's function in the transcriptional regulation of cellular processes. The highly divergent $\mathrm{C}$-terminal TAR regions of NAC proteins are thought to confer transcriptional activation of specific cellular functions including developmental and defense signaling pathways $[19,26,27]$. In yeast, the Cterminal TAR region of ATAF2 functioned to induce lacZ gene expression (Figure 4A), confirming ATAF2's role as a transcriptional activator. Subsequently, a hexa-histidinetagged ATAF2 protein readily functioned to pull-down Arabidopsis genomic DNA derived from the promoter regions of diverse genes. A representative sequence located within $1000 \mathrm{bp}$ of the translational start site for the defensin-like protein At1G68907 was subsequently used to identify a 30-bp sequence that functioned as a cisregulatory binding sequence for ATAF2. Most notably when co-expressed in planta with ATAF2 this 30-bp sequence directed the expression of a GUS reporter construct (Figure 4B). This 30-bp sequence also directed in planta GUS expression in response to a TMV infection (Figure 5). Thus, the induction of endogenous ATAF2 in response to infection is sufficient to drive gene expression from the identified ATAF2 binding sequence. Tissue wounding is also known to induce the transcription of ATAF2 [6,7]. Subsequent analysis of the transcript levels from nine of the original ATAF2 pull-down clones showed that eight were transcriptionally reduced by at least 2 fold in wounded tissues of the ATAF2 $\mathrm{KO}$ line in comparison to wounded tissues of the wild-type plant line (Table 2). The reduced transcriptional activation of these genes in the absence of ATAF2 indicates that ATAF2 contributes to the transcriptional regulation of these genes, further confirming the importance of the identified ATAF2 binding sequence within the promoters of these genes.

Wound induced activation of genes identified in the original ATAF2 pull-down assay indicated that these genes contain ATAF2 specific binding sequences. Motif analysis searches using the identified 30-bp binding sequence and promoter sequences shown to regulate gene expression upon the induction of ATAF2 or bind ATAF2 directly showed the presence of a 25 -bp consensus sequence that was subsequently found in all analyzed pulldown sequences (Table 1). The identified 25-bp sequence is $\mathrm{A} / \mathrm{T}$ rich and contains repeats of a [CG] AAA motif either consecutively or in reverse orientation. Previous studies have identified several NAC family
DNA binding elements. In one study, in vitro selection was used to identify the DNA binding site of two functionally diverse NAC proteins: ANAC019, implicated in stress, and ANAC092, implicated in morphogenesis [16]. A core binding element of CGT[GA] was identified. This sequence is the reverse complement of the core binding sequence identified from three NAC proteins (ANAC019, ANAC055, and ANAC072) that recognizes a 63-bp sequence harboring CACG as the core DNA binding site [28]. Combined these findings suggest that diverse NAC proteins can bind similar sequences. However, other NAC proteins appear to bind different sequences. For example, NAC1 binds to a 21-bp DNA fragment containing an as-1 element (TGACG) [19]. In wheat, a NAC protein binding consensus sequence was identified as [AG]G[AT]NNCGT[AG]NNNNN[CT] ACGT[AC]A[CT][CT] [29]. These previously identified NAC binding sequences including their core binding motifs are not present within the identified ATAF2 binding sequence, suggesting that ATAF2 recognizes a binding sequence different from that used by other NAC proteins. The A/T rich nature of the ATAF2 binding domain does have similarities to other plant based transcription binding domains. For example, the regulatory region of the pea plastoxyanin gene promoter is similarly $\mathrm{A} / \mathrm{T}$ rich and is recognized by proteins containing high mobility group box domains that presumably modulate gene expression [30]. This diversity in sequence recognition reflects the large family of NAC proteins and the wide range of functions assigned to this TF family.

The 30 bp length of the DNA nuclease protected fragment and its nearly complete requirement for activity as determined by mutagenesis studies (Figure 6,7) suggested ATAF2 functions as a multimer. This is consistent with previous studies that have shown several NAC proteins form and function as dimers $[19,20]$. In addition, crystallographic data for ANAC019 reveals an antiparallel $\beta$-sheet flanked by $\alpha$-helices with a defined dimer interface that promotes both homo- and hetero-interactions along with a positively charged face that is thought to promote DNA binding [1,31]. To confirm the oligomeric status of ATAF2, purified ATAF2 NAC domain was examined through a size exclusion chromatography and a peak representing a dimeric form of the NAC domain was observed (Figure 8). Oligomerization of bacterial purified ATAF2 NAC domain suggests that ATAF2 likely functions as a dimer. Whether the functional ATAF2 oligomer is a homodimer or heterodimer formed with another NAC protein is unknown, but it is clear that the induction of ATAF2 in response to wounding or stress is required for the transcriptional activation of gene promoters encoding the identified binding sequence.

The role of ATAF2 in basal defense is not as yet resolved. However, it is interesting to note that several of 
the ATAF2 target genes identified in this study have links to defense responses. For example, Polyamine Oxidase 3 protein (PAO3) displays significant transcript reductions within ATAF2 $\mathrm{KO}$ tissues, indicating it is positively regulated by ATAF2 (Table 2). Furthermore, polyamines are known to accumulate in response to a number of environmental stresses including pathogen attack [32]. PAO3 functions within the peroxiosome, catalyzing accumulated polyamines and producing $\mathrm{H}_{2} \mathrm{O}_{2}$ [33]. Uehara et al. [34] proposed the production of $\mathrm{H}_{2} \mathrm{O}_{2}$ from the catalysis of polyamines functions as a signal transducer for the activation of defense responses. Another example is the Oxidative Stress 3 protein (OXS3), which is also positively regulated by ATAF2. OXS3 is required for resistance to cadmium and co-localizes to the nucleus with the nucleosomal histone protein $\mathrm{H} 4$ where it is thought to function as a remodeling factor, moving the location of the nucleosome and altering gene expression [35]. Interestingly, cadmium treatment is linked to TMV resistance in plants and is correlated with the deposition of callose within the plasmodesmata and vascular tissues [36,37]. Ueki and Citovsky [38] identified a cadmium induced Glycine-Rich Protein (cdiGRP) that localizes to the vascular cell walls and promotes callose deposition. Overexpression of cdiGRP enhanced TMV resistance while its knockdown results in increased virus spread. In both of the above examples, ATAF2 directed regulation of PAO3 and OXS3 could enhance virus resistance via the production of $\mathrm{H}_{2} \mathrm{O}_{2}$ and the induction of cdiGRP, respectively. Such defense responses indicate that TMV's targeted degradation of ATAF2 functions as an anti-defense countermeasure. However, confirming the role of ATAF2 in regulating these resistance pathways and their effect on mediating defense against TMV requires additional studies.

\section{Conclusion}

We report here the identification of the ATAF2 binding sequence and its function in gene regulation in response to wounding and TMV infection. Identification of this binding sequence represents a significant step toward identifying the basal defense processes associated with ATAF2 expression as well as understanding the TMV counterdefenses targeting these processes.

\section{Methods}

Plant material, agroinfiltration, wounding, and virus inoculations

Plants were grown at $23^{\circ} \mathrm{C}$ under a 10 hour light / 14 hour dark cycle. Agroinfiltrations were done as previously described [39]. In summary, Agrobacterium tumefaciens strain GV3101 carrying the desired expression constructs were grown at $30^{\circ} \mathrm{C}$ overnight. Cultures were concentrated by centrifugation and resuspended in infiltration medium (10 mM MES, pH 5.7, $10 \mathrm{mM}$
$\mathrm{MgCl}_{2}, 150 \mu \mathrm{M}$ acetosyringone) to an $\mathrm{OD}_{600}$ of 0.5 prior to leaf infiltration. Forty-eight hours post-agroinfiltration, the plant tissues were processed as described below. For wounding treatment, fully matured leaves of four-week old plants were wounded several times across the mid-vein using razor blades. Five hours after the wounding, the leaves were harvested and processed for analysis. For virus inoculations, TMV solutions of 0.1 to $0.5 \mathrm{mg} / \mathrm{ml}$ were rubinoculated onto carborundum-dusted leaves.

\section{Plasmid constructs and protein expression}

The full-length coding sequence of ATAF2 (AT5g08790) and its truncated version containing only the NAC domain (ATAF2-165, 1 aa to 165 aa) were each PCRamplified to contain 5' XhoI and 3' KpnI sites. The amplified fragments were ligated into the expression vector pTrcHisA (Life Technologies, Grand island, NY) to create pTrcHisA/ATAF2 and pTrcHisA/ATAF2-165 with N-terminus hexa-histidine tags. The $\triangle \mathrm{ATAF} 2$ deletion construct was created by PCR-amplification of ATAF2 fragments covering nucleotides 1 to 171 with 5' XhoI and 3' PstI sites and nucleotides 376 to 852 with 5' NsiI and 3' KpnI sites. The two fragments were ligated together into $X h o I$ and KpnI cut pTrcHisA vector, to generate $\mathrm{pTr}$ HisA/ $\triangle \mathrm{ATAF} 2$. The purification of recombinant his-tagged ATAF2 and $\triangle$ ATAF2 proteins was conducted as described previously [39]. Briefly, Escherichia coli BL21 (+) cells were grown at $37^{\circ} \mathrm{C}$ to an $\mathrm{OD}_{600}$ of 0.5 followed by pTrcHisA induction at $16^{\circ} \mathrm{C}$ with $1 \mathrm{mM}$ isopropyl-1-thio- $\beta$-d-galactopyranoside. Bacterial cells were harvested and resuspended in lysis buffer containing $10 \mathrm{mM}$ Tris, $\mathrm{pH}$ 8.0, 10\% glycerol (v/v), $500 \mathrm{mM}$ $\mathrm{NaCl}$, and $10 \mathrm{mM}$ imidazole. After sonication and centrifugation $(17,000 \mathrm{~g}$ for $10 \mathrm{~min})$, cell extracts were incubated with $1 \mathrm{ml}$ (bed volume) of Ni-NTA affinity column (GE Healthcare, Piscataway, NJ) at $4^{\circ} \mathrm{C}$ for $1-$ $2 \mathrm{~h}$. The column was then washed with 10 column volumes of wash buffer (lysis buffer plus $10 \mathrm{mM}$ imidazole). Proteins were eluted in buffer (lysis buffere plus $140 \mathrm{mM}$ imidazole). Eluted proteins were analyzed by SDS-PAGE and protein concentration was determined via Bradford assay [40].

For the GUS reporter gene constructs, the -49 CaMV $35 \mathrm{~S}$ minimal promoter and tandem repeats of 30-bp ATAF2 binding sequence were sequentially introduced into the pBI101 vector (Clonetech, Palo Alto, CA), upstream of the $\beta$-glucuronidase (GUS) coding sequence. In summary, two primers $\left(5^{\prime}\right.$-TCGACCGCAAGACCCTTCCTCTATATAAGGAAGTTCATTTCATTTGGAGAGGAG-3' and $5^{\prime}$-GATCCTCCTCTCCAAATGAAATGAACTTCCT TATATAGAGGAAGGGTCTTGCGG-3') covering the -49 to +1 region of the CaMV $35 \mathrm{~S}$ promoter were inserted via 
SalI and BamHI sites (underlined) into pBI101 to generate $\mathrm{pBI} / 35 \mathrm{SM}-\mathrm{GUS}$. Primers carrying two copies of the 30-bp ATAF2 binding sequence and a $\mathrm{XbaI}$ restriction site (5'-AGCTTGTCTAGAGATCAGAAGAGCAATCAA ATTAAAACACATATTAGGATCAGAAGAGCAATCAAA TTAAAACACATATTAGG- $3^{\prime}$ and $5^{\prime}$-TCGACCTAATAT GTGTTTTAATTTGATTGCTCTTCTGATCCTAATATG TGTTTTAATTTGATTGCTCTTCTGATCTCTAGACA$\left.3^{\prime}\right)$ were then introduced into $\mathrm{pBI} / 35 \mathrm{Sm}$-GUS at the HindIII and SalI sites (underlined) to create pBI/2X30bpGUS. Similarly, two more copies of the 30-bp sequence (5'-AGCTTGATCAGAAGAGCAATCAAATTAAAACAC ATATTAGGATCAGAAGAGCAATCAAATTAAAACA CATATTAGT-3' and 5'-CTAGACTAATATGTGTT TTAATTTGATTGCTCTTCTGATCCTAATATGTGTTT TAATTTGATTGCTCTTCTGATCA-3') were introduced into the HindIII and XbaI sites of pBI/2X30bp-GUS to generate $\mathrm{pBI} / 4 \mathrm{X} 30 \mathrm{bp}-\mathrm{GUS}$. All three GUS reporter gene constructs were transformed into Agrobacterium tumefaciens strain GV3101 [41].

\section{Size exclusion chromatography}

The purified ATAF2 NAC domain (ATAF2-165) was incubated in buffer containing $25 \mathrm{mM}$ Tris- $\mathrm{HCl} \mathrm{pH} \mathrm{7.5,} \mathrm{10 \%}$ glycerol (v/v), $500 \mathrm{mM} \mathrm{NaCl}$, and $0.5 \mathrm{mM}$ EDTA for $20 \mathrm{~min}$ at room temperature. The incubated protein $(\sim 160 \mu \mathrm{g})$ was then run through a Superdex-200 HR $10 / 30$ column (GE Healthcare, Piscataway, NJ) preequilibrated with the incubation buffer. Fractions $(250 \mu \mathrm{l})$ were collected and a portion of each $(50 \mu \mathrm{l})$ analyzed by SDS-PAGE, followed by Coomassie blue staining.

\section{Genomic pull-down assay}

Plant genomic DNAs were extracted from four-week old Arabidopsis ecotype Shahdara leaf tissue using a standard CTAB genomic DNA isolation method [42]. Plant tissues were ground in CTAB buffer containing 2\% Hexadecyl trimethyl-ammonium bromide, $100 \mathrm{mM}$ Tris, $\mathrm{pH}$ 8.0, $20 \mathrm{mM}$ EDTA, 1.4 M NaCl, and $0.2 \% \beta$-mercaptoethanol. After incubation at $55^{\circ} \mathrm{C}$ for 1 hour, the CTAB/ plant extract mixture was centrifuged at 12,000 $\mathrm{g}$ for $10 \mathrm{~min}$. The supernatant was collected and the genomic DNA extracted with phenol/chloroform followed by ethanol precipitation.

Target sequences of ATAF2 were identified using a genomic pull-down assay described previously [18]. Briefly, Arabidopsis genomic DNA was digested with EcoRI and TaqI and ligated to two short linker sequences with corresponding restriction sites [18]. The DNA fragments were then incubated with recombinant his-tagged ATAF2 followed by precipitation with anti-polyHis antibody and protein A agarose (Life Technologies, Grand island, NY, Carlsbad, CA). After removing the bound protein with phenol/chloroform, the DNA fragments were PCR amplified and cloned into pCRII using TOPO TA Cloning Kit (Life Technologies, Grand island, NY).

\section{Electrophoretic mobility shift assays (EMSAs)}

Double-stranded DNA probes were prepared either by PCR-amplification or by annealing complementary singlestranded DNA together. DNA probes were 5 ' end-labeled with $\left[\gamma^{-}{ }^{32} \mathrm{P}\right] \mathrm{ATP}$ via T4 polynucleotide kinase (New England Biolabs, Ipswich, MA). For EMSA assays 100 to 300 fmol of each gel-purified labeled DNA fragment was mixed with various concentrations of purified ATAF2 protein in a $10 \mu \mathrm{l}$ reaction containing $20 \mathrm{mM}$ Tris- $\mathrm{HCl}, \mathrm{pH}$ 8.0, $60 \mathrm{mM} \mathrm{KCl}, 5 \mathrm{mM} \mathrm{MgCl} 2,100 \mu \mathrm{g} / \mathrm{ml} \mathrm{BSA,} \mathrm{5 \%} \mathrm{gly-}$ cerol, $1 \mathrm{mM}$ DTT, and $0.5 \mu \mathrm{g}$ poly $(\mathrm{dI}-\mathrm{dC})$. Binding reactions were incubated at $25^{\circ} \mathrm{C}$ for $30 \mathrm{~min}$, and then loaded onto a $5 \%(\mathrm{w} / \mathrm{v})$ native polyacrylamide gel. Electrophoresis was carried out in $0.5 \mathrm{X}$ TBE buffer at $100 \mathrm{~V}$ for $2-3 \mathrm{~h}$. Gels were vacuum-dried onto filter paper and visualized via PhosphorImager (Molecular Dynamics, Sunnyvale, CA). Quantitative analysis of DNA binding affinity of recombinant ATAF2 was performed on scanned gels using the ImageJ analysis tool.

\section{DNase I footprinting}

5 ' end-labeled DNA probe fragments were loaded on 5\% non-denaturing polyacrylamide gels. After gel electrophoresis, probes were excised and recovered after diffusion overnight into $10 \mathrm{mM}$ Tris- $\mathrm{HCl}, 1 \mathrm{mM}$ EDTA, $\mathrm{pH}$ 8.0. The DNA-protein binding reaction was carried out as described above using purified ATAF2 protein (20 $\mathrm{nM}$ or $200 \mathrm{nM}$ ) and $10 \mathrm{fmol}$ of probe DNA. This mixture was incubated for $30 \mathrm{~min}$ at $25^{\circ} \mathrm{C}$ followed by the addition of $50 \mu \mathrm{l}$ of $\mathrm{Ca} / \mathrm{Mg}$ solution $\left(5 \mathrm{mM} \mathrm{CaCl}_{2}\right.$ and $10 \mathrm{mM} \mathrm{MgCl}_{2}$ ). One minute later, $3 \mu \mathrm{l}$ of RQ1 DNase, diluted at least 1:100 (determined empirically) from a $1 \mathrm{mg} / \mathrm{ml}$ stock, was added. RQ1 digestion was terminated after 1 min with $90 \mu \mathrm{l}$ of 20 mM EGTA. Reactions were extracted with phenol:chloroform:isoamyl alcohol (25:24:1), and the DNA precipitated with ethanol and subjected to denaturing urea-polyacrylamide gel electrophoresis, followed by visualization using PhosphorImager (Molecular Dynamics, Sunnyvale, CA)

\section{GUS assays}

GUS activity within plant tissue was visualized by histochemical staining with 5-bromo-4-chloro-3-indolyl- $\beta$-Dglucuronic acid (X-Gluc) as described previously [6]. For quantitative measurements of GUS activity, a modified fluorimetric GUS assay was used [43]. Briefly, plant tissues were ground in extraction buffer containing $150 \mathrm{mM}$ sodium phosphate, $\mathrm{pH}$ 7.0, $10 \mathrm{mM}$ EDTA, $10 \mathrm{mM} \beta$-mercaptoethanol, 0.1\% Triton X-100, 0.1\% sarcosyl, and $140 \mu \mathrm{M}$ PMSF. After pelleting at 20,000 $\mathrm{g}$ for 
15 mins, fluorometric substrate 4-methyl-umbelliferyl- $\beta$ D-glucuronide (4-MUG) was added to the supernatant to a final concentration of $1.0 \mathrm{mM}$. The mixed product was incubated in darkness at $37^{\circ} \mathrm{C}$ for 20 mins. $10 \mu \mathrm{l}$ aliquots were then taken from each reaction and mixed with $190 \mu \mathrm{l}$ stop buffer $\left(0.2 \mathrm{M} \mathrm{Na}_{2} \mathrm{CO}_{3}\right)$ in a black-wall clear-bottom 96-well plate. The fluorescent 4Methylumbelliferone (MU) produced in the GUS reaction was measured using a SpectraMax M2 microplate reader (MTX Lab systems, Vienna, VA) with excitation at $365 \mathrm{~nm}$ and emission at $455 \mathrm{~mm}$. A standard curve derived from six MU standards was included with every plate. Protein concentration in the extracts was determined by Bradford assay [40]. Final GUS activity was expressed as pmoles MU/min/mg protein. All experiments were repeated twice and the nonspecific GUS activity was normalized according to the relative GUS activity driven by the CaMV $35 \mathrm{~S}$ minimal promoter.

\section{Real-time qRT-PCR}

Leaf tissue from three to five individual test plants were pooled for RNA extraction. Total RNA was extracted using the RNeasy RNA extraction kit (Qiagen, Valencia, CA). $1 \mu \mathrm{g}$ of total RNA was pre-treated with RQ1 DNase (Promega, Madison, WI) and used in a first strand cDNA synthesis reaction with SuperScript ${ }^{\mathrm{TM}}$ II reverse transcriptase (Life Technologies, Grand island, NY). Real-time qRT-PCR reactions were performed using SYBR green PCR mix (Fermentas, Glen Burnie, MD) and an ABI Prism 7100 (Applied Biosystems, Foster City, CA) as previously described [6]. The 18 s rRNA was used as an internal control for normalization Primer sequences used for each of the selected genes are listed in Additional file 1: Table S1.

\section{Statistical analysis}

Identification of statistically overrepresented motifs was done by using the motif search MEME program [22]. The 30-bp short ATAF2-binding sequence together with each selected candidate target genes identified from the genomic pull-down assay were chosen for the analysis. The motif search options were defined as "one occurrence per sequence" and motif width was set to be between 25 and $30 \mathrm{bp}$.

\section{Additional file}

Additional file 1: Table S1. Primers used for real-time qRT-PCR.

\section{Abbreviations}

TFs: Transcription factors; NAC: NAM, ATAF1/2, CUC2; SA: Salicylic acid; TMV: Tobacco mosaic virus; EMSĀA Electrophoretic mobility shift assay; KO line: Knockout line.

\section{Competing interests}

The authors declare that they have no competing interests.

\section{Authors' contributions}

XW and JNC conceived, designed and wrote the manuscript. XW performed all experiments. Both authors read and approved the final manuscript.

\section{Acknowledgements}

We would like to thank Drs. Rong Guo and Anne Simon for assistance with the DNase I footprinting analysis and Drs. Miao Pan and Zvi Kelman for help with the size-exclusion chromatography study. This work was support in part by grants from USDA National Research Initiative Competitive Grants (200835319-19168) and NSF (ISO-1120044).

Received: 7 June 2012 Accepted: 6 August 2012

Published: 31 August 2012

\section{References}

1. Olsen AN, et al: NAC transcription factors: structurally distinct, functionally diverse. Trends Plant Sci 2005, 10(2):79-87.

2. Singh K, Foley RC, Onate-Sanchez L: Transcription factors in plant defense and stress responses. Curr Opin Plant Biol 2002, 5(5):430-436.

3. Rushton PJ, Somssich IE: Transcriptional control of plant genes responsive to pathogens. Curr Opin Plant Biol 1998, 1(4):311-315.

4. Boch J, Bonas U: Xanthomonas AvrBs3 family-type III effectors: discovery and function. Annu Rev Phytopathol 2010, 48:419-436.

5. Endres MW, et al: Two plant viral suppressors of silencing require the ethylene-inducible host transcription factor RAV2 to block RNA silencing. PLoS pathogens 2010, 6(1):e1000729.

6. Wang X, Goregaoker SP, Culver JN: Interaction of the Tobacco mosaic virus replicase protein with a NAC domain transcription factor is associated with the suppression of systemic host defenses. J Virol 2009, 83(19):9720-9730.

7. Delessert $C$, et al: The transcription factor ATAF2 represses the expression of pathogenesis-related genes in Arabidopsis. Plant J 2005, 43(5):745-757.

8. Ooka $\mathrm{H}$, et al: Comprehensive analysis of NAC family genes in Oryza sativa and Arabidopsis thaliana. DNA Res 2003, 10(6):239-247.

9. Aida $M$, et al: Genes involved in organ separation in Arabidopsis: an analysis of the cup-shaped cotyledon mutant. The Plant cell 1997, 9(6):841-857.

10. Guo Y, Gan S: AtNAP, a NAC family transcription factor, has an important role in leaf senescence. The Plant journal: for cell and molecular biology 2006, 46(4):601-612.

11. Uauy $C$, et al: A NAC Gene regulating senescence improves grain protein, zinc, and iron content in wheat. Science 2006, 314(5803):1298-1301.

12. Collinge $M$, Boller T: Differential induction of two potato genes, Stprx2 and StNAC, in response to infection by Phytophthora infestans and to wounding. Plant Mol Biol 2001, 46(5):521-529.

13. Hegedus D, et al: Molecular characterization of Brassica napus NAC domain transcriptional activators induced in response to biotic and abiotic stress. Plant Mol Biol 2003, 53(3):383-397.

14. Xie $Q$, et al: GRAB proteins, novel members of the NAC domain family, isolated by their interaction with a geminivirus protein. Plant Mol Biol 1999, 39(4):647-656.

15. Ren T, Qu F, Morris TJ: HRT gene function requires interaction between a NAC protein and viral capsid protein to confer resistance to turnip crinkle virus. Plant Cell 2000, 12(10):1917-1926.

16. Olsen AN, et al: DNA-binding specificity and molecular functions of NAC transcription factors. Plant Science 2005, 169(4):785-797.

17. Kim HS, et al: Identification of a calmodulin-binding NAC protein as a transcriptional repressor in Arabidopsis. J Biol Chem 2007, 282(50):36292-36302.

18. Miao Y, et al: Targets of the WRKY53 transcription factor and its role during leaf senescence in Arabidopsis. Plant Mol Biol 2004, 55(6):853-867.

19. Xie $Q$, et al: Arabidopsis NAC1 transduces auxin signal downstream of TIR1 to promote lateral root development. Genes Dev 2000, 14(23):3024-3036.

20. Olsen AN, et al: Preliminary crystallographic analysis of the NAC domain of ANAC, a member of the plant-specific NAC transcription factor family. Acta Crystallogr D: Biol Crystallogr 2004, 60(Pt 1):112-115.

21. Bailey $\mathrm{TL}$, et al: MEME SUITE: tools for motif discovery and searching. Nucleic Acids Res 2009, 37(Web Server issue):W202-W208. 
22. Bailey $T L$, Elkan C: Fitting a mixture model by expectation maximization to discover motifs in biopolymers. Proceedings / ... International Conference on Intelligent Systems for Molecular Biology; ISMB. International Conference on Intelligent Systems for Molecular Biology 1994, 2:28-36.

23. Carr JP, Lewsey MG, Palukaitis P: Signaling in induced resistance. Advances in virus research 2010, 76:57-121.

24. Singh DP, et al: Activation of multiple antiviral defence mechanisms by salicylic acid. Molecular plant pathology 2004, 5(1):57-63.

25. Lee WS, et al: Genetic modification of alternative respiration in Nicotiana benthamiana affects basal and salicylic acid-induced resistance to potato virus X. BMC plant biology 2011, 11:41.

26. Seo PJ, et al: Cold activation of a plasma membrane-tethered NAC transcription factor induces a pathogen resistance response in Arabidopsis. The Plant journal: for cell and molecular biology 2010, 61(4):661-671

27. Duval $M$, et al: Molecular characterization of AtNAM: a member of the Arabidopsis NAC domain superfamily. Plant Mol Biol 2002, 50(2):237-248.

28. Tran $L S$, et al: Isolation and functional analysis of Arabidopsis stressinducible NAC transcription factors that bind to a drought-responsive cis-element in the early responsive to dehydration stress 1 promoter. The Plant cell 2004, 16(9):2481-2498.

29. Xue GP: A CELD-fusion method for rapid determination of the DNAbinding sequence specificity of novel plant DNA-binding proteins. The Plant journal: for cell and molecular biology 2005, 41(4):638-649.

30. Webster $\mathrm{Cl}$, et al: High mobility group proteins HMG-1 and HMG-I/Y bind to a positive regulatory region of the pea plastocyanin gene promoter. The Plant journal: for cell and molecular biology 1997, 11(4):703-715.

31. Ernst HA, et al: Structure of the conserved domain of ANAC, a member of the NAC family of transcription factors. EMBO Rep 2004, 5(3):297-303.

32. Hussain SS, et al: Polyamines: natural and engineered abiotic and biotic stress tolerance in plants. Biotechnol Adv 2011, 29(3):300-311.

33. Moschou PN, et al: Bridging the gap between plant and mammalian polyamine catabolism: a novel peroxisomal polyamine oxidase responsible for a full back-conversion pathway in Arabidopsis. Plant Physiol 2008, 147(4):1845-1857.

34. Uehara $Y$, et al: Tobacco ZFT1, a transcriptional repressor with a Cys2/ His2 type zinc finger motif that functions in spermine-signaling pathway. Plant Mol Biol 2005, 59(3):435-448.

35. Blanvillain $R$, et al: OXIDATIVE STRESS 3 is a chromatin-associated factor involved in tolerance to heavy metals and oxidative stress. The Plant journal: for cell and molecular biology 2009, 57(4):654-665.

36. Zavaliev $R$, et al: Biology of callose (beta-1,3-glucan) turnover at plasmodesmata. Protoplasma 2011, 248(1):117-130.

37. Ueki S, Citovsky V: The systemic movement of a tobamovirus is inhibited by a cadmium-ion-induced glycine-rich protein. Nature cell biology 2002, 4(7):478-486.

38. Ueki S, Citovsky V: Identification of an interactor of cadmium ion-induced glycine-rich protein involved in regulation of callose levels in plant vasculature. Proc Natl Acad Sci U S A 2005, 102(34):12089-12094.

39. Wang X, Kelman Z, Culver JN: Helicase ATPase activity of the Tobacco mosaic virus $126-k D a$ protein modulates replicase complex assembly. Virology 2010, 402(2):292-302.

40. Bradford MM: A rapid and sensitive method for the quantitation of microgram quantities of protein utilizing the principle of protein-dye binding. Anal Biochem 1976, 72:248-254.

41. Holsters M, et al: Transfection and transformation of Agrobacterium tumefaciens. Mol Gen Genet 1978, 163(2):181-187.

42. Doyle JJ, Doyle JL: Isolation of plant DNA from fresh tissue. Focus 1990 12:13-15.

43. Jefferson RA, Kavanagh TA, Bevan MW: GUS fusions: beta-glucuronidase as a sensitive and versatile gene fusion marker in higher plants. EMBO 1987, 6(13):3901-3907.

doi:10.1186/1471-2229-12-157

Cite this article as: Wang and Culver: DNA binding specificity of ATAF2, a NAC domain transcription factor targeted for degradation by Tobacco mosaic virus. BMC Plant Biology 2012 12:157.

\section{Submit your next manuscript to BioMed Central and take full advantage of:}

- Convenient online submission

- Thorough peer review

- No space constraints or color figure charges

- Immediate publication on acceptance

- Inclusion in PubMed, CAS, Scopus and Google Scholar

- Research which is freely available for redistribution 